\title{
Influence of Parenting Styles on the Social Development of Children
}

\author{
Mensah, Monica Konnie \\ Kuranchie, Alfred \\ Faculty of Education, Catholic University College of Ghana, Fiapre-Sunyani \\ Email kuranchiealf@yahoo.com
}

Doi:10.5901/ajis.2013.v2n3p123

\begin{abstract}
The purpose of the study was to ascertain the dominant parenting styles of parents in the study area and their influence on children's social development. The study utilised a sample of 480 basic school pupils who were in their adolescent stage and 16 teachers. The survey study employed a structured interview schedule and a questionnaire for the data collection. The study instruments were pre-tested to establish their validity and reliability. The results of the study revealed that the majority of the parents were perceived to adopt authoritative parenting styles in the upbringing of their children. It was also revealed that parenting style has influence on students' social development. It is inferred that authoritative parenting based on reasoning, understanding, consensus and trust resulted in pro-social behaviour while authoritarian parenting based on strict rules, force, threat, verbal and physical punishments resulted in anti-social behaviour. It is, therefore, recommended that parents should endeavour to adopt authoritative parenting style to enable their children and wards to develop pro-social behaviour. The significance of the study is that the results would help parents, guardians, teachers and school authorities to understand and appreciate the relationship between parenting style and children's social development. Parents, in particular, would be fascinated by the findings of the study to employ authoritative parenting style to aid their children to be socially competent, a virtue required for personal life and work ethos.
\end{abstract}

Keywords: Parenting styles, social behaviour, authoritative, authoritarian and permissive parenting styles and academic achievement.

\section{Introduction}

Right from infancy, children learn and acquire traits and behaviours that they exhibit throughout their life time. During socialization, parents and other authoritative figures endeavour to form children in such a way as to make them acquire worthwhile virtues cherished by the society. Parents customarily are obligated to play this all- important role of socializing their children into their social milieu as primary agents of socialisation. They are expected to become an important influence on the emotional, cognitive and social development of children (Hughes, Kroehler \& Zanden, 1999). It is believed that there are some roles that are better performed by parents which children tend to accept most readily than any other person in their life. Since parental roles are essentially formative, their influence in the socialization of children cannot be over-emphasised. It is this understanding that precipitated this study which aimed at examining the influence of parenting behaviours and their activities on children's educational outcomes. Most of the studies on parenting styles have emphasised that the kind of parenting style adopted by parents has monumental impact on children's attitude, academic achievement and career choice (Maccoby \& Martin 1983; Mandara, 2006). This underscores why children raised in entirely different environments but received the same kind of parenting tend to exhibit similar characteristics and behaviours. Different parenting styles produce different characteristic traits of children including those demonstrated at school.

\section{Problem Statement}

The way and manner children are brought up is reckoned to be very essential to the development of the growing child. This underscores Gadeyne, Ghesquiere and Onghena (2004) assertion that parenting is an important determinant which affects the whole child. The way parents take care of their children impacts on the latter's personality development and their ways of interacting with social and close relations. This role is very influential in children's development. Child development psychologists have particularly paid attention to this phenomenon and that many studies have been conducted to ascertain the veracity of the issue (Baumrind, 1991, Bloir, 1997, Kracke, 1997, Kerka, 2000). Most of these 
studies mainly investigated the influence of parenting styles on children's academic performance at school. The findings of the studies have been consistent to suggest that authoritative parenting style correlates with good academic performance. There is, however, dearth of data on the influence of parenting styles on students' social behaviour which is considered a non-academic gain. Existing studies have mainly assessed the influence of parenting styles on the academic trajectory of students' learning outcomes virtually oblivious of students' social development. Meanwhile, the development of competent social skills of students is an objective of education (Ten Dam \& Volman, 2007). Students who go through formal education are expected to be competent both academically and socially. Given the apparent significance of being socially competent at school and at the world of work, it was deemed worthwhile investigating the influence of parenting style on children's sociability. The focus of the study, therefore, was on the role of parenting style on social development of the adolescent child. Intrinsically, the research sought empirical-based evidence on the relationship between parenting styles and child's social development since there is dearth of data to that effect.

\section{Rationale of the Study}

The study intended to unearth how parents impact on children's development with the following objectives: (i) investigate the dominant parenting styles of parents in the study area, and (ii) ascertain the relationship between parenting styles and children's social competence.

\section{Research Question and Hypothesis}

What is the dominant parenting style of parents in the study area?

Ho: There is no relationship between parenting styles and children's social competence

\section{Theoretical Framework}

\subsection{Parenting Styles}

The concept parenting style is viewed as a characteristic of a parent that changes the effectiveness of family socialisation practices and children's receptiveness to such practices (Darling \& Steinberg, 1993). Parenting styles are broad patterns of childrearing practices, values, and behaviours. It is the way parents take care of their children which can have impact on the children's personality development and the ways of interacting with social and close relations (Akhtar, 2012). While various typologies of parenting styles have been developed and utilised in literature, Baumrind (1991) typology (authoritative, authoritarian and permissive styles) has largely been accepted as very comprehensive. Consequently, the current study utilised this typology to assess the relationship between parenting styles and children's social development.

\subsection{Authoritative Parenting Style}

The authoritative style balances clear, high expectations with emotional support and recognition of children's autonomy. The authoritative parent tries to direct the child, but in a rational manner (Baumrind, 1991). Such a parent encourages give and take but shares the reasoning behind his or her rules. These parents value both autonomous self-will and disciplined conformity. They exercise firm control with certain points but the child is not tied up with restrictions (Baumrind, 1991). Authoritative parents provide a warm family climate, set standards and promote independence, which result in more active career exploration on the part of children (Kracke 1997). This sort of parenting is characterised by high levels of nurturance, involvement, sensitivity, reasoning and encouragement of autonomy. They provide a positive emotional climate for their children in order to promote autonomy and support assertiveness and individuality. Authoritative parents are assertive but intrusive and restrictive. Their disciplinary methods are supportive rather than punitive. Parents who direct the activities and decisions for their children through reasoning and discipline are described as authoritative (Turner, Chadler \& Heffer, 2009).

\subsection{Authoritarian Parenting Style}

The authoritarian parent tries to shape, control, and evaluate the behaviour and attitudes of the child in accordance with a set standard of conduct (Baumrind, 1991). Obedience is a virtue and punitive measures are used to curb self-will. When 
the child expresses actions or beliefs that are at variance with parent's or when the child's actions or beliefs go contrary to what the authoritarian parent deems as a good conduct, the child is panelised. This type of parenting tries to institute respect of authority, respect for work and preservation of order and traditional structure. Verbal give and take is not encouraged and the parent's word should be accepted as right, willy-nilly. Parents characterised as authoritarian exhibit highly directive behaviours, high levels of restriction and rejection behaviours and power-asserting behaviours of children (Turner, et al 2009). Maintenance of structure and order are high priorities for these parents. These parents are highly demanding and unresponsive.

\subsection{Permissive Parenting Style}

The permissive parent attempts to behave in a non-punitive, accepting, and affirmative manner towards the child's impulses, desires, and actions (Baumrind, 1991). With this type of parenting, few demands are made of the child regarding such things as chores. This type of parenting does not require the parent to act as an active agent responsible for shaping or altering the child's behaviour (Baumrind, 1991). The child is allowed to regulate his or her own activities. The parent does not control the child nor encourages the child to obey external standards. Parents who adopt this type of parenting consider self-regulation to be the right of a child to live freely without outside authority. Those who support this type of parenting style feel that punishment has inevitable negative side effects and it is an ineffective means of controlling behaviour. They also feel that close supervision, high demands, and other manifestations of parental authority provoke rebelliousness in children. According to those who espouse this parenting type, firm parental control generates passivity and dependence in the child (Baumrind, 1991). Permissive parenting is characterised by making few demands, exhibiting non-controlling behaviours and using minimal punishment. These parents are warm and responsible but not demanding and have few expectations of their children. Parents who do not set rules and regulations for their children's behaviour are described as possessing a permissive parenting style (Turner, et al, 2009).

The important role of parenting practices in the development of the child has garnered research attention of educationists. Consequently, a plethora of researches has been conducted to determine how significantly parenting styles are related to student cognitive and psycho-motor development. Dornbousch, Rither, Liederman, Roberts and Fraleigh (1987) conducted a study to find the relationship between parenting styles and student learning achievement. The study utilised school performance of 7,836 high school adolescents in San Francisco. The students' performance was based on a measure of self-reported grade averages and questionnaire was used to obtain indirect measures of parenting style. The results revealed that authoritative parenting style was positively correlated with students' school grades while authoritarian and permissive styles were negatively correlated with school grades. The relationship was consistent across ethnic, parents' education, gender and age. Studies have also established that children raised by authoritative parents scored higher on measures of academic competence, achievement, self-perceptions, and mental health than do children reared by the other three parenting types (Steinberg, Lamborn, Darling, Mounts, \& Dornbusch, 1994).

Strage and Brandt (1999) studied the role of parenting styles in the live of college students and found that previous parenting behaviours continue to be important in the lives of the students. The more autonomy, demand and support parents provided, the more students were confident and persistent academically as with children and adolescents. In a related study, Shaw (2008) found a relationship between academic self-efficacy and parenting styles. The study examined the relationship between parenting styles and academic self-efficacy and college adjustment of 31 fresh engineering students. The study reported strong academic self-efficacy in students of authoritative parents than those of other parents.

A study by Aunola, Stattin and Nurmi (2002) set out to investigate the extent to which adolescents' academic strategies were associated with the parenting styles they experienced in their families. The results unveiled four types of families: authoritative, authoritarian, permissive and neglectful parenting styles. The study further disclosed that adolescents from authoritative families applied most of the adaptive achievement strategies characterised by low levels of failure expectations and task-irrelevant behaviours unlike their cohorts from other families. The parenting styles adopted in the upbringing of the children had great influence on the children's choice of academic strategies.

Tay and Tam (2011) also studied the relationship between parenting styles and coping capability of adolescent children. The survey study that used 140 students found that parenting styles correlated with adolescents' coping capability. It emerged that authoritarian paternal and authoritative maternal parenting correlated with adolescents' coping capability. On his part, Starr (2011) examined the relationship among the styles of parenting, learning autonomy, perceived parental autonomy support and scholastic achievement of undergraduate students. The results revealed 
positive and negative correlations between many of the variables in the study. Parenting styles had a significant and positive direct effect on achievement motive for female students but not for male students. However, Cramer's (2002) study found a positive relationship between parenting styles and classroom motivation of the students.

Hickman, Suzanne and McKeny (2000) also examined relationship between parenting styles and academic performance and adjustment in college students. Parental Authority Questionnaire (PAQ) was used to assess respondents' perceptions of parenting styles while self-reported college grade point (GPA) was used to assess student academic achievement. The study unveiled that authoritative parenting style was positively correlated with students' academic achievement, while permissive and authoritarian styles negatively correlated with students' achievement.

A comparative study was carried out by Gary, Levin, Urajnik and Kauppi (2005) to examine parenting styles, family characteristics and academic achievement using sample of Canadian and East Indian adolescents. Items in the questionnaire, the instrument used to gather data were based on acceptance and strictness. The results of the study disclosed that the percentages of self-reported authoritative parenting style were similar in both Canadian and East Indian samples. On parents using authoritarian parent style, there were differences. While $35 \%$ of the Canadian sample used it, $19 \%$ of the East Indian sample used it. In the Canadian sample, it was realised that authoritative parenting style was related to highest academic achievement but with the East Indian sample there was no relationship.

Yusuf (2004) set out to investigate the influence of parenting styles on junior secondary school students' performance in social studies. Questionnaire and proforma were used to collect data on parenting styles and students' performance. The data on junior school certificate and parenting styles were analyzed using frequency count, percentages and chi- square to answer the research questions and test the hypotheses raised in the study. The results showed that the parenting styles adopted had influence on the performance of the students. It was also realised that students from authoritative parenting had better performance than students from other parenting styles.

Differences exist in the academic performance of children with authoritative parents and those with authoritarian and permissive parents and that parenting style is a major predictor of student academic achievement. Authoritative parenting style is associated with high academic achievement. Authoritative parenting style tends to emphasis both responsiveness and demandingness which appears superior in fostering higher academic performance (Reitman, Rhode, Hopp \& Altobello, 2002). There is, however, dearth of knowledge on the influence of parenting styles on social competence of pupils. Do children of authoritative parents behave better than those of authoritarian and permissive parents? This question needed empirically-based evidence, hence the need for the study.

\section{Methodology}

\subsection{Research Design and Population}

Descriptive survey design was used to execute the study. The population of the study composed of the basic school pupils and teachers in the Sunyani East and West Educational Districts of the Brong Ahafo region of Ghana. Four hundred and eighty (240 males and 240 females) pupils and sixteen (16) teachers were randomly sampled from eight (8) public and private basic schools to provide data for the exercise. The pupils were utilized to elicit responses to determine the parenting styles of their parents while the teachers were tasked to rate certain personality traits and behaviours that the pupils usually exhibit in their social relations with and attitude towards other students and staff. Hence, students' social competence and development were ascertained from teachers' rating of the students' behaviours exhibited in school.

\subsection{Instrumentation}

The relevant data of the study were obtained using two sets of instruments (questionnaire and interview schedule) designed by the researchers. The questionnaire was developed to gather data from students on their perceived parents' styles of parenting. The questionnaire which was a 23 -item instrument had two sections. Section "A" elicited studentrespondents' personal data while Section "B" made up of 18 items was directed at finding out the perceived parenting styles of the students' parents. The second instrument, a structured interview schedule, was used to elicit information on students' comportment in school. The teachers rated students' behaviours such as co-operativeness, sobriety, assertiveness, impulsive behaviour and the likes. Both instruments had a likert rating scale of 4-1 in a descending order for positive items and reverse for negative items. The face validity of the instruments was determined by peer review. The instruments were also pre-tested on 60 students and three teachers to assess their reliability. The pre-testing of the 
instruments was done using Cronbach alpha and the results of the questionnaire and the interview schedule were 0.78 and 0.76 respectively. These reliability co-efficients of the research instruments were deemed high enough to warrant their usage to gather data for the main study.

\subsection{Data Collection and Analysis Method}

The researchers personally administered the instruments to the respondents in their respective schools after permission had been obtained from the schools' authorities and verbal consent of the pupils. The rapport established between the researchers and the respondents engendered a high response rate and instructions were scrupulously followed. The statistical software, Statistical Package for Social Sciences (SPSS) version 16, was used to analyse the data collected. The data were arranged in the required format and keyed into the software for the processing. The statistical tests were performed at 0.05 alpha level using Pearson Product Moment Correlation Coefficient.

\section{Results of the Study}

The exercise intended to ascertain the dominant parenting styles and their relationship with children's development. Table 1 presents the results of the parenting styles the subjects perceived their parents utilise in their upbringing.

Table 1: Parenting styles of respondents' parents

\begin{tabular}{ccc}
\hline Parenting style & Frequency & Percent \\
\hline Authoritative & 330 & 68.7 \\
Authoritarian & 80 & 16.7 \\
Permissive & 70 & 14.6 \\
\hline Total & $\mathbf{4 8 0}$ & 100 \\
\hline
\end{tabular}

The results show that the dominant parenting style as perceived by the pupils is authoritative style. Majority of the students ( $n=330,68.7 \%)$ perceive their parents to be authoritative. Such students see their parents demonstrating features of authoritativeness. Parents who are described as such exhibits behaviours such as encouraging children to talk about their problems, guiding them by reasoning, giving praise when kids behave well and the likes.

Only a few of them perceived their parents to be authoritarian $(n=80,16.7 \%)$ followed by permissiveness $(n=70$, 14.6\%). Thus, eighty (16.7\%) of them regarded their parents as authoritarian probably because the parents do exhibit behaviours such as setting strict rules for the children to follow, spanking the kids when they disobey rules, not offering explanation for punishing the children and administering verbal and physical punishments to the children.

It is very pertinent and heartwarming to realise that most parents in the area adopt authoritative parenting style which has the tendency to make children develop expressive behaviour. This would make the children to freely share their personal, social and academic worries with their parents for appropriate solutions as well as sharing their plans with them for proper directions. This development has the tendency to make the children eschew the practice of taking solace in their immature colleagues with its attendant problems. As noted by Chipper, Hanisch, Creed \& McGregor (2006), in the absence of parents' help, the adolescent child would develop social relationships with non-familial adults and peers for assistance. So if the non-familial adults and peers are morally deficient, their influence on the children could be grievous and detrimental to their future progress.

Table 2: Relationship between parenting styles and social development

\begin{tabular}{ccccc}
\hline & & Authoritative & Authoritarian & Permissive \\
\hline \multirow{3}{*}{ Social competence } & Pearson correlation & .214 & .117 & .103 \\
& Significant level (2-tailed) & .031 & .046 & .512 \\
& $\mathrm{~N}$ & 330 & 80 & 70 \\
\hline
\end{tabular}

The findings of the study show relationship between parenting style and child social outcomes. The results of the study depict a positive correlation between authoritative parenting styles and good social behaviour. The sig., .031, shows a positive and significant relationship between authoritative parenting style and good conduct. This connotes that children of authoritative parents exhibit pro-social behaviours such as co-operativeness, sobriety, empathy etc in their relationship 
with their peers and staff hence the teachers rating them as socially competent. This style of parenting was effective in shaping the lives of the children hence making them put up acceptable behaviours in school.

The results also demonstrate a relationship between authoritarian parenting style and social incompetence. It is realised that authoritarian parenting style has a negative relationship (-046) with pupils' behaviour. Children of authoritarian parents were rated by their teachers as socially incompetent. This style of parenting was not effective in controlling and shaping the children's behaviour. The results, however, did not show any relationship between permissive parenting style and students' conduct.

From the results, the hypothesis that there is no relationship between parenting style and students' social development is rejected. Evidence suggests that there is a relationship between authoritative and authoritarian parenting styles and children's social development. Children of authoritative parents behave better than those of authoritarian parents and vice- verse.

Generally, the results of the study are consistent with the findings of positive correlation between parenting styles and academic performance found by Dornbousch, Rither, Liederman, Roberts and Fraleigh (1987), Hickman, Suzanne and McKeny (2000) and Yusuf (2004), and positive relationship between parenting styles and classroom motivation of students (Cramer, 2002).

This revelation points out that authoritative parenting style is very essential to most learning outcomes while authoritarian parenting style is inimical to pupils' academic and non-academic achievements.

\section{Conclusions and Recommendations}

The study unveiled that a disproportionate chunk of parents of the children adopt authoritative style of parenting by showing responsiveness, warmth and caring behaviour at home. In this time and age, parents are supposed to treat their kids as rational beings to enable them to come out of themselves. Children of such parents may be able to avoid negative peer influence and risky behaviours as they would confide in the parents as well as discussing their problems and plans with them. The study also revealed a relationship between parenting styles and children's sociability. Children of authoritative parents were graded as socially competent while those of authoritarian parents were rated socially incompetent. Implicit in this finding is that, the way and manner children are brought up affect their social development. The results of the relationship between parenting style and social behaviour of children have added to the repertoire of existing studies that have found positive and significant relationship between parenting style and children's academic achievement. The parenting behaviours and activities that children experience at home have a great impact on their conduct and learning at school. It is plausible to aver that parenting styles have influence on children's total development. These amply demonstrate that parents can have a great impact on their children's educational outcomes (Miki, 2008) and that parenting styles and parenting practices shape children's development (Steinberg, et al, 1992, Gadeyne, et al, 2004).

It is, therefore, necessary for parents to be well aware of the negative and positive impacts of the various parenting styles on students' academic and non-academic gains. Parents ought to be educated on the importance of adopting the parenting style that would aid in promoting their children's development. Educators and counselors could use fora like PTA meetings, Speech and Prize Giving Days, Open Days and Anniversaries to educate parents on the influence of parenting styles on children's development. Through this, educators would help parents nurture the virtuous child for the millennium. The child who would possess not only the knowledge and competencies needed for societal progress and development but also the cherished values and attitudes which are pre-requisite for social cohesion and integration, and national development.

\section{References}

Akhtar, Z. (2012). The effect of parenting style of parents on the attachment styles of undergraduate students. www.languageinindia.com. Retrieved on 15th October, 2012.

Aunola, K., Stattin, H. and Nurmi, J. (2002). Parenting styles and adolescents' strategies. Journal of Adolescence, 23 (2), 205 - 222.

Baumrind, D. (1991). The influence of parenting style on adolescent competence and substance use. Journal of Early Adolescence, 11(1), 56-95.

Bloir, K. (1997). Parenting that promotes resilient urban African American families: Scholars describe the characteristics of their parents' parenting behaviours.

Cramer, K. E. (2002). The influence of parenting styles on children's classroom motivation. Master's Thesis. Louisiana State University.

Darling. N. and Steinberg, L. (1993). Parenting style as context: An integrative model. Psychological Bulletin, 113, 487-496.

Dornbusch, S. M., Ritter, P. L., Leiderman, P. H., Roberts, D. F. and Fraleigh, M. J. (1987). The relation of parenting style to adolescent school performance. Child Development, 58(5), 1244-1257. 
Gadeyne, E., Ghequiere, P. and Oghena, P. (2004). Longitudinal relations between parenting and child adjustment in young children. Journal of Clinical Child and Adolescent Psychology, 22, 347-358.

Garg, R., Levin, E., Urajnik, D. and Kauppi, C. (2005). Parenting styles and academic achievement for East Indian and Canadian adolescents. Journal of Comparative Family Studies, 36(4), 653-662.

Hickman, G. P., Bartholomae, S. and McKenry, P. C. (2000). Influence of parenting styles on the adjustment and academic achievement of traditional college freshmen. Journal of College Student Development, 41(1), 41-54.

Kracke, B. (1997). Parental behaviours and adolescents' career exploration. Career Development Quarterly, 45 (4), 341 - 350.

Maccoby, E. E. and Martin, J. A. (1983). Socialization in the context of the family: Parent-child

interaction. In E. M. Hetherington (Ed.) and P. H. Mussen (ed.), Handbook of Child

Psychology, Socialization, Personality, and Social Development. New York: Wiley.

Reitman, D., Rhode, P. C., Hupp, S. D. A. and Altobello, C. (2002). Development and validation of the Parental Authority QuestionnaireRevised. Journal of Psychopathology and Behavioral

Assessment, 24, 119-127.

Shaw, H. E. (2008). The relationship between perceived parenting style and academic self-efficacy and college adjustment. M Sc Thesis, University of North Texas.

Starr, M. L. (2011). The relationship between parenting styles, learning autonomy and scholarship achievement in undergraduate college students. http://digital.commons .bucknell.edu//masters theses. Retrieved on 10th October, 2012.

Steinberg L., Dornbusch, S. M. and Brown B. B (1992). Ethnic differences in adolescent achievement: An ecological perspective. American Psychologist, 47 (4), 723-729.

Strage, A. A. and Brandt, T. S. (1999). Authoritative parenting and college students' academic adjustment and success. Journal of Educational Psychology, 9 (1), 146-156.

Tay, E. L. and Tam, C. L. (2011). Relationship between perceived parenting styles and coping capability among Malaysian secondary school students. Proceedings of International Conference on Social Science and Humanity, 2, 20 - 23.

Turner, E. A., Chandler, M. and Heffer, R. W. (2009). Influence of parenting styles, achievement motivation, and self-efficacy on academic performance in college students. Journal of College Student Development, 50(3), 337-346.

Yusuf, A. (2004). Effect of cooperative instructional strategy on students' performance in social studies. Nigeria Journal of Social Studies $8(2), 23-36$. 
